\title{
Stormwater Management in Airport using Oil Water Separator System
}

\author{
Velautham KD ${ }^{1,2}$, Chelliapan $\mathrm{S}^{1}$, Kamaruddin $\mathrm{SA}^{1}$, Meyers $\mathrm{JL}^{2}$ \\ ${ }^{1}$ Department of Engineering and Technology, Razak Faculty of Technology and Informatics, UniversitiTeknologi Malaysia, \\ 54100, Jalan Sultan Yahya Petra, Kuala Lumpur, Malaysia \\ ${ }^{2}$ SWA Water Malaysia Sdn Bhd., D-2-2, Megan Avenue 1, 189 JalanTunRazak, 50400 Kuala Lumpur, Malaysia \\ Corresponding author:ChelliapanS,Department of Engineering and Technology, Razak Faculty of Technology and \\ Informatics, UniversitiTeknologi Malaysia, 54100, Jalan Sultan Yahya Petra, Kuala Lumpur, Malaysia.
}

\begin{abstract}
Oil contamination in the stormwater has been generally overlooked, even though it causes major environmental pollution and is a substantial threat to all the species in the ecosystem. Likewise, the treatment of oilcontaminated stormwater in public areas and general industries, especially in airports, has largely been ignored. Airports are known as one of the most potent oil contamination contributors through the jet fuel that pollutes the local waterways and stormwater. However, little information regarding the specific actions taken to treat the stormwater contaminated with jet fuel oil in airport facilities, is available.The objective of this paper is to discusses the stormwater management that using the oilwater separator system in airports contaminated with oil. Specifically, this paper highlights the contaminants of stormwater run-off from airports and the oil-water separator system in airports. The use of a corrugated plate interceptor (CPI) for stormwater management in airports was discussed.The success in treating stormwater largely depends on the improvement of infrastructure, the capturing of pollutants and nutrients from the stormwater flows, in addition to the use of wetlands to improve the ecology and water quality of streams and rivers. Incorporating an oil-water separator system into the stormwater treatment system in the airports setting is quite significant since the airport is known for its large and paved areas containing oil, grease or jet fuel.The treatment of the airports stormwater contaminated with oil, grease and jet fuel could significantly reduce the contamination for a cleaner environment. The CPI can be used to separate the oils from the water and then retains the oils safely until removal.
\end{abstract}

Keywords: Oil Water Separator, Stormwater Management, Airport, Jet Fuel, Corrugated Plate Interceptor

\begin{abstract}
1 Introduction
Stormwater quality and quantity management are among the major concerns of the developing nations due to the increasing rate of urbanisation that leads to an increase in the stormwater run-off quantity. This situation significantly deteriorates its quality and affects the aquatic environment. ${ }^{1,2}$ Consequently, the urban stormwater treatment field is becoming one of the major research topics in many countries. In the developed nations, the success in treating stormwaterdepends on the improvement of infrastructure, the capturing of pollutants and nutrients from the stormwater flows, and the use of wetlands to improve the ecology and water quality of streams and rivers. Moreover, these nations also have many stringent rules and regulations for the water from washing activities, for instance, from the car wash centres, car workshops, restaurants, hotels. It is mandatory for these centres to have silt traps, grease traps, oil-water separators, and others. However, many third world and developing countries do not implement or impose any laws or rules on these types of premises, so the wash water quality was not improved or treated before it enters local waterways. ${ }^{3}$
\end{abstract}

Beside the stormwater run-off from urban areas, the stormwater run-off at airports is also a significant and costly issue. The airports stormwater treatment management is primarily exercised in most developed countries due to its huge catchment area and its naturally and highly contaminated surface run-off compared to the other types of surface run-off. ${ }^{4}$ Therefore, airports are one of the key important areas for the stormwater surface run-off treatments before the stormwater is being discharged into the watercourse. The activities which are contributing to the water and air pollutions in airport are such as fueling operations, cleaning of aircraft, and the combustion of aviation fuel. ${ }^{5}$ Some of the key contamination elements in the airports surface run-off include the slitter, sand, dirt, grease, oils and especially jet fuels. In addition, stormwater run-off is a huge non-point source of heavy metal ions. ${ }^{6}$

It is important to have a suitable facility to treat airport wastes since it is a significant contributor to water pollution. Moreover, a special treatment is required for the airports drainage since it contains oil-based byproducts. The rainwater from the paved areas can be cleaned in a special treatment plant with the separation of oil products located inside the airport, or alternatively, with a collector connected to the local municipal treatment plant. ${ }^{7}$ Furthermore, the areas such as the fuel storage, aircraft hangars, and the maintenance facilities, should be equipped with oil traps. ${ }^{8}$ Many of the airport facilities are experiencing stormwater contamination from oils. Most of these contaminations come from leaking and spilling jet fuel tank associated fuelling stations, storage tanks, and vehicle maintenance operations. ${ }^{9}$ The rainwater mixing with oil is commonly collected in the containment basins. This solution mixture often contains small amounts of hydrocarbons. Hence, it is necessary to remove the oil from the water before discharging it from the airport facility. 


\section{Contaminants of Stormwater Runoff from Airports}

Many studies on the stormwater run-off from the airports had been carried out throughout and around the world. The effluents from airport operations have mainly consisted of the stormwater run-off from paved surfaces, followed by the sanitary wastewater from public and employee services and from the aeroplanes. Stormwater run-off may include the pollutants associated with leaks and spills of oil, diesel, and jet fuels, produced during the operation and maintenance of ground service vehicles fuel storage and handling activities. In the cold climates, airports stormwater run-off may include aircraft de-icing/anti-icing fluids that typically contain ethylene or propylene glycol, as well as the runway and taxiway de-icing/ant icing fluids that typically contain potassium acetate, sodium acetate, calcium magnesium acetate, or the mixtures of urea and water. Although these chemicals are biodegradable, their direct discharge into the surface waters through the stormwater drainage network can negatively impact the aquatic environments through increasing the oxygen demands, as well as enhancing the eutrophication process caused by the nutrients released from de-icing chemicals (e.g., the nitrogen from urea and phosphorus from glycol). ${ }^{10}$ The differences in the chemical composition of fuels can help identify the source of contamination by chemical fingerprinting, as indicated in Table 1.

Table 1. Weight distribution of some hydrocarbons and heavy metals in fuels and oils ${ }^{11}$

\begin{tabular}{|c|c|c|c|c|c|}
\hline Chemical & Gasoline & Diesel & Jet A1 (JP-8) & Jet B (JP-4) & Oils \\
\hline \multicolumn{6}{|l|}{ Metals (mg/L) } \\
\hline As & - & - & - & - & 5 \\
\hline $\mathrm{Ba}$ & - & - & $<0.3$ & - & 48 \\
\hline $\mathrm{Cd}$ & - & - & - & - & 3 \\
\hline $\mathrm{Cr}$ & 0.0027 & - & - & - & 5 \\
\hline $\mathrm{Pb}$ & $0.13-1.1$ & 0.17 & $<0.3$ & - & 240 \\
\hline $\mathrm{Mg}$ & - & - & 9.6 & - & - \\
\hline $\mathrm{Mb}$ & - & - & 1.9 & - & - \\
\hline $\mathrm{Ni}$ & - & 0.27 & $<1$ & - & - \\
\hline $\mathrm{Ti}$ & - & - & 2.7 & - & - \\
\hline $\mathrm{V}$ & - & - & $<0.6$ & - & - \\
\hline $\mathrm{Zn}$ & - & - & 2.4 & - & 480 \\
\hline \multicolumn{6}{|l|}{ Aromatics (\%) } \\
\hline Benzene & 2.34 & $<0.013$ & 0.0082 & 0.50 & 0.002 \\
\hline Ethylbenzene & 1.90 & 0.031 & 0.06 & 0.37 & - \\
\hline Toluene & 8.21 & 0.036 & 0.08 & 1.33 & 0.038 \\
\hline m-Xylene & 3.50 & & & & \\
\hline o-Xylene & 2.71 & 1.95 & 3.56 & 2.32 & 0.055 \\
\hline p-Xylene & 3.50 & & & & \\
\hline $\begin{array}{l}\text { Polyaromatic } \\
\text { Hydrocarbons (PAH) } \\
\text { total }\end{array}$ & $5.6-10.7$ & $5.2-10.9$ & 2.66 & 1.81 & \\
\hline Naphthalene & \begin{tabular}{|l|}
$0.09-0.49$ \\
\end{tabular} & $0.035-0.16$ & $0-0.5$ & 0.50 & 0.033 \\
\hline \multicolumn{6}{|l|}{$\begin{array}{l}\text { Halogenated } \\
\text { hydrocarbons (mg/L) }\end{array}$} \\
\hline $\begin{array}{l}\text { Trichloroethylene } \\
\text { (TCE) }\end{array}$ & - & - & - & - & 100 \\
\hline $\begin{array}{l}\text { Tetrachloroethylene } \\
\text { (PCE) }\end{array}$ & - & - & - & - & 106 \\
\hline $\begin{array}{l}\text { Polychlorinated } \\
\text { biphenyls (PCBs) }\end{array}$ & - & - & - & - & 5 \\
\hline
\end{tabular}

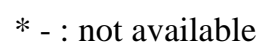

\section{Oil Water Separator in Airport}

There are many types of oil water separators that are being used in airports worldwide. However, since the environmental regulation of oils in the water discharges is increasing and becoming more stringent; thus, the airport oil-water separators specifications and designs are also becoming increasingly complicated. The possible applications of coalescing plate separators found inside the oil-water separators include the fuel farm stormwater, fueling trucks, fueling aprons, and vehicle maintenance operations. ${ }^{12}$ For the fuel farm stormwater and fueling aprons, the oil-water separators must treat the contaminated water before discharged into the surface waters. The methods for removing oils from water range from very simple tanks to very elaborate membrane technology- 
based systems. The oil-water separation methods include gravity separation, centrifugal separation, electric dehydration separation, chemical processing, and coalescence separation. ${ }^{13-15}$ The centrifugal separation and electric dehydration separation processes require additional equipment hence increase the energy consumption. Meanwhile, chemical treatment depends on chemical agents and thus may cause secondary pollution. Additionally, the cost of related equipment needed for chemical treatment is high. The corrugated plate oil-water separation technology is the organic combination of gravity separation and coalescence separation. This technology is currently a hot spot for researchers and for many companies due to its feasibility, low operating cost and effectiveness. ${ }^{16}$ Unfortunately, the findings based on the microscopic experiments and mechanisms revealed that the applications of corrugated plate packs for oil-water separation are insufficient. This weakness strongly hindered the further optimisation of the technology. Table 2 shows the comparison of the oil-water separation techniques.

Table 2. The comparison of the oil-water separation techniques ${ }^{17}$

\begin{tabular}{|c|c|c|}
\hline Techniques & Advantages & Disadvantages \\
\hline Gravitational & $\begin{array}{l}\text { Effective for discrete phases of oil and } \\
\text { water }\end{array}$ & $\begin{array}{l}\text { Not effective to separate emulsified oils from } \\
\text { water }\end{array}$ \\
\hline Centrifugation & $\begin{aligned} \text { I. } & \text { More compact } \\
\text { II. } & \text { Do not require large bilge water } \\
& \text { holding tanks } \\
\text { III. } & \text { Produce small amount of waste } \\
\text { IV. } & \text { Can be run without continuous } \\
& \text { man-hours operation and } \\
& \text { supervision }\end{aligned}$ & $\begin{array}{cl}\text { I. } & \text { Use huge horsepower motors } \\
\text { II. } & \text { Require frequent maintenance } \\
\text { III. } & \text { High capital cost for centrifuges }\end{array}$ \\
\hline Flotation & $\begin{aligned} \text { I. } & \text { Less investment needed } \\
\text { II. } & \text { Low energy consumption } \\
\text { III. } & \text { Easy to maintain } \\
\text { IV. } & \text { Produce less sludge }\end{aligned}$ & $\begin{array}{cl}\text { I. } & \text { Repairing and maintenance problem } \\
\text { II. } & \text { Issue in manufacturing of the device }\end{array}$ \\
\hline $\begin{array}{l}\text { Coagulation and } \\
\text { flocculation }\end{array}$ & $\begin{array}{cl}\text { I. } & \text { Can remove emulsified oil and } \\
\text { dissolved oil } \\
\text { II. } & \text { High adaptability }\end{array}$ & $\begin{aligned} \text { I. } & \begin{array}{l}\text { Need to be operated by skillful } \\
\text { operator }\end{array} \\
\text { II. } & \text { High operating cost } \\
\text { III. } & \begin{array}{l}\text { Produce high amount of sludge which } \\
\text { then needs to be disposed }\end{array} \\
\text { IV. } & \begin{array}{l}\text { A lot of experiments might be needed } \\
\text { due to complexity of wastewater } \\
\text { composition }\end{array}\end{aligned}$ \\
\hline Biological & $\begin{aligned} & \text { I. } \begin{array}{l}\text { Able to effectively degrade } \\
\text { organic pollutants including } \\
\text { emulsified oil }\end{array} \\
& \text { II. } \text { Can remove other organic } \\
& \text { pollutants } \\
& \text { III. } \text { No waste oil produced } \\
& \text { IV. } \text { Mechanically simple } \\
& \text { V. } \text { Low operating cost }\end{aligned}$ & $\begin{aligned} \text { I. } & \text { Loading spikes can occur } \\
\text { II. } & \text { High capital cost } \\
\text { III. } & \text { Need to be operated by skillful } \\
& \text { operator }\end{aligned}$ \\
\hline $\begin{array}{l}\text { Absorption and } \\
\text { adsorption }\end{array}$ & $\begin{array}{cl}\text { I. } & \text { Suitable for less than } 400 \mathrm{GT} \\
& \text { vessels } \\
\text { II. } & \text { Relatively compact } \\
\text { III. } & \text { Low capital and operation costs } \\
\text { IV. } & \text { Require low maintenance }\end{array}$ & $\begin{array}{l}\text { I. Need to replace the media frequently } \\
\text { (if necessary) }\end{array}$ \\
\hline
\end{tabular}

A Corrugated Plate Separator (CPS) is the most effective separation and treatment technologies used so far in separating the oils from water. The corrugated plate packs applied for oil-water separation originated from American Petroleum Institute (API). ${ }^{18}$ The separation tank can be categorised as a gravity oil-water separation device and has many advantages like simple structure, easy-maintainability and high oils removals efficiency. The corrugated plates provide tortuous channels for the fluids to flow back and forth; this subsequently optimises the coalescence of dispersed droplets. There are many types of corrugated plate packs developed since 1950, such as the Parallel Plate Interceptor (PPI), Coalescence Plate Separator (CPS), and the Corrugated Plate Interceptor (CPI), and the designs modifications of plate packs. ${ }^{18-21}$ Situated at the heart of the 
CPS, the CPI minimises the rising distance of oil droplets before coming into contacts with other oil droplets. Although the PPI separator offers an important improvement in separating the oils from water, the efficiency is low. In the search to optimise the oily water separation, the CPI was jointly developed by Shell's engineers, Jan Cornelissen and Jacob Pielkenrood. ${ }^{22}$ This CPI is utilised in most of the industries until now. Basically, this is an advanced version of PPI where the plates are placed in the basin at a certain inclined angle (normally $45^{\circ}$ ) and allow the oils to rise along with the lower plate parts, consequently, coagulate to become larger droplets via corrugation peak. ${ }^{23}$ There are many factors, such as flow field, initial oil concentration, followed by the structural parameters such as length, oil-water separation efficiency, plate spacing, and surface properties of materials that are affecting the separation efficiency of CPI.

\section{Corrugated Plate Interceptor (CPI)}

The results and the conclusions of prior experiments described that the efficiency of CPI against the pollution by fuel or hydrocarbons was high, but only if the fuel or hydrocarbons are available freely and in abundance. ${ }^{24}$ The separators are adapted to intercept the massive pollutions from fuel distribution areas, car wash utilities, airports and accidental discharges. On the contrary, the applications of separators are less relevant for car parks and roads with a low concentration of pollution traces. It is also not confirmed that the fuel hydrocarbons coming from motor vehicles will be soaked into the concrete and eventually washed by the water. Thus, the applications of CPI are therefore more adapted for industrial treatment than for the treatment of run-off waters. ${ }^{25}$ There is also a mix up due to the settling tank that is present inside the upstream of the separator, but this tank is not designed to intercept with the fixing hydrocarbon type. In fact, the liquid-liquid separation of hydrocarbons requires an ascending velocity of about $8 \mathrm{~m} / \mathrm{h}$, while the purification by sedimentation requires a descending velocity of between 1 to $3 \mathrm{~m} / \mathrm{h} .{ }^{26} \mathrm{~A}$ different approach would be necessary for the treatment of urban run-off because of the nature and characteristics of the run-off. For example, the lamellar sedimentation approach is the most adapted alternative that uses sedimentation techniques, followed ideally by the separation of oil. ${ }^{27}$

Moreover, the cleaning of CPI may not improve the purifying efficiency, as the dysfunctions issues most of the time have resulted from poor maintenance. Hence, this shows the importance of maintenance and control programs for the best separator performances. Meanwhile, an extracted hydrocarbons quantities inventory should be organised by the municipalities. ${ }^{28}$ The maintenance that is rarely being carried out or was carried out by someone who is not qualified can cause issues of rusticity and robustness. Moreover, insulation is also recommended in order to limit acts of vandalism. The setting of measuring equipment and alarms (for examples, the captors that detect the sludge levels and the probe that detect the hydrocarbons levels) is necessary for better reliability and better optimisation of operating costs. For better management, these alarms can be adjusted as a remote monitoring system. ${ }^{29}$

There are also some important differences between the separators behaviours, due to the different types of watersheds. Several parameters, such as the discharge, effluents, the length and frequency of rain events, as well as pollution, need to be considered to determine the installation and designs choices for the pre-treatment works. The CPI quality is not the only parameter that needs to be considered, and the choice needs to be adapted for optimal precision of conditions and uses. The needs for preliminary studies and treatment trials before the adoption of each water purifier are necessary to quantify and qualify the run-off waters, along with to use the results as the choices and designs basis for the separators.

The adapted standards are written and are distinguished into a few groups, such as (1) the standards adapted for the effluent treatment of chronic hydrocarbons pollution coming from the surfaces (fuel distribution areas), (2) the standards adapted for the trapping of highly concentrated and accidental discharges (from the sites susceptible to the pollution caused by the activities that are possibly combined with a vulnerable natural environment) and finally, (3) the standards adapted to the purification of run-off waters. The standards for runoff waters purification are based on the purifying efficiency and are assessed according to the purifying efficiency of suspended solids. ${ }^{30}$ By taking into considerations about the above findings, the major contaminants found in the airports stormwater run-off is confirmed to consists of fuel/hydrocarbon and sediments/suspended solids and with the tropical climatic condition, thus meaning that there are no de-icing or anti-icing agents used. The CPI must be installed as close as possible to the effluentsources that need to be treated. Therefore, the CPI is frequently found along the motorways. The preliminary data collections collected showed that the United States (US), the leading country in terms of having the latest available technology, has the highest CPI number installed in the airports than the other countries from around the world. Table 3 shows the summary of the CPI installation by the Highland Tank \& Mfg. Co. (the pioneer company in CPI manufacturing and installing) in the US airports. The actual reference list showing the oil-water separators installed in the airports is quite substantial, so the list in the table below only shows the summary of their biggest airport installation. The oil-water separator units involved have been designed to treat the stormwater run-off with the minimum flow rates capacity of not less than $5001 / \mathrm{s}$ or $1800 \mathrm{~m} 3 / \mathrm{hr}$.

Table 3. Installation of the CPI by Highland Tank \& Mfg. Co, in the US Airports which are more than 500/s 


\begin{tabular}{|c|c|c|c|c|}
\hline No. & Airport & Flow rate $(\mathrm{l} / \mathrm{s})$ & Quantity & Model \\
\hline \multirow[t]{7}{*}{1} & Cincinnati/Northern & 95 & 1 & HT 15000 \\
\hline & Kentucky Airport & 570 & 3 & НTC30000 \\
\hline & Cincinnati, $\mathrm{OH}$ & 252 & 1 & HTC40000 \\
\hline & & 630 & 2 & HTCC50000 \\
\hline & & 252 & 1 & HTCC40000 \\
\hline & & 380 & 2 & HTCC 30000 \\
\hline & & $2 \frac{95}{2274}$ & 1 & HT15000 DWI \\
\hline \multirow[t]{2}{*}{2} & Newark International & 63 & 1 & HT10000 \\
\hline & Airport Newark, NJ & $\underline{756}$ & 4 & HTCC30000 DWI \\
\hline \multirow[t]{2}{*}{3} & Denver International & $\overline{126}$ & 2 & HTC10000 \\
\hline & Airport Denver, CO & $\frac{630}{756}$ & 2 & $\begin{array}{c}\text { HTC-EZ-50000 } \\
\text { DWI }\end{array}$ \\
\hline \multirow[t]{4}{*}{4} & John Wayne Airport & $\overline{158}$ & 1 & HT25000 \\
\hline & Orange County, CA & 315 & 2 & HTC25000 DWI \\
\hline & & $\underline{630}$ & 2 & HTC50000 DWI \\
\hline & & $\underline{1103}$ & & \\
\hline \multirow[t]{2}{*}{5} & Lambert International & 76 & 1 & HT12000 \\
\hline & Airport St. Louis, MO & $\underline{504}$ & 4 & HTC20000 DWI \\
\hline 6 & New Orleans Airport & $\overline{1262}$ & 4 & HT 50000 \\
\hline 7 & $\begin{array}{l}\text { Rockford Airport UPS } \\
\text { Rockford IL }\end{array}$ & 631 & 2 & HT50000 \\
\hline
\end{tabular}

\section{Conclusion}

Stormwater quality and quantity management areamongthe major concerns in many countries, stems from the high urbanisation development rate that leads to an increasing amount of stormwater run-off. Even though the higher amount of run-off may significantly deteriorate its quality and toxicity, but the impacts on the aquatic environment are critical. The success in treating stormwaterlargely depends on the improvement of infrastructure, the capturing of pollutants and nutrients from the stormwater flows, in addition to the use of wetlands to improve the ecology and water quality of streams and rivers. Incorporating an oil-water separator system into the stormwater treatment system in the airports setting is quite significant since the airport is known for its large and paved areas containing oil, grease or jet fuel. Hence, the treatment of the airports stormwater contaminated with oil, grease and jet fuel could significantly reduce the contamination for a cleaner environment. Specifically, the CPI can be used to separate the oils from the water and then retains the oils safely until removal.

\section{Acknowledgment}

The authors thank Ministry of Education, Malaysia for funding this research under the MyBrain $15 \mathrm{PhD}$ Industry Scholarship Grant and UniversitiTeknologi Malaysia. This research also was partially funded by UniversitiTeknologi Malaysia using UTM Prototype Research grant; Vote Number: Q.K130000.2856.00L57.

\section{References}

1.Shishegar S, Duchesne S, Pelletier G, Ghorbani R. A smart predictive framework for system-level stormwater management optimization. Journal of Environmental Management, 2021; 278 (1):111505.

2.Cramer M, RinasM, KotzbauerU, TräncknerJ. Surface contamination of impervious areas on biogas plants and conclusions for an improved stormwater management. J Clean Prod 2019; 217: 1-11.

3.Ando AW, Cadavid CL, Netusil NR, Parthum B. Willingness-to-volunteer and stability of preferences between cities: Estimating the benefits of stormwater management. Journal of Environmental Economics and Management. 2020; 99: 102274.

4.Ko D, Kim H, Lee H, Yavuz CT, Andersen HR, Hwang Y. Applicability of disulfide- polymer particles surface embedded on alginate beads for cadmium removal from airport derived stormwater. Journal of Environmental Chemical Engineering. 2018; 6: 4124-4129.

5.BlackwellBF, DeVaultTL, Fernández-JuricicE, DolbeerRA. Wildlife collisions with aircraft: A missing component of land-use planning for airports. Landscape and Urban Planning 93 (2009) 1-9.

6.Dongah Ko, Hyowon Kim, Hansaem Lee, Cafer T. Yavuz, Henrik R. Andersen, Yuhoon Hwang, Applicability of disulfide-polymer particles surface embedded on alginate beads for cadmium removal from airport derived stormwater, Journal of Environmental Chemical Engineering 2018; 6 (4): 4124-4129. 
7.Astebøl SO, Hvitved-Jacobsen T, SimonsenO. Sustainable stormwater management at Fornebu - From an airport to an industrial and residential area of the city of Oslo, Norway. Science of The Total Environment 2005; 334-335:239-49.

8.Sulej-Suchomska AM, Polkowska Z, Kokot ZJ, de la Guardia M, Namieśnik J. Determination of antifreeze substances in the airport runoff waters by solid-phase microextraction and gas chromatography-mass spectrometry method.Microchemical Journal 2016; 126: 466-473.

9.CarvalhoIC, CalijuriML, AssemanyPP, Machado e Silva MDF, NetoRFM, Santiago AF, et al. Sustainable airport environments: A review of water conservation practices in Recycling 2013; 74: 27-36. airports. Resources, Conservation and

10.US EPA (US Environmental Protection Agency) 2007. Reducing stormwater costs through low impact development (LID) strategies and practices (EPA 841-F-07-006). EPA, Washington, DC; 2007.

11.Nunes, L.M., Zhu, Y., Stigter, T.Y., Monteiro, J.P., and Teixeira, M.R., 2011,

Environmental Impacts on Soil and Groundwater at Airports: Origin, Contaminants of Concern and Environmental Risks, J. Environ. Monit., 13(11), 30-26.

12.Ashraf MA, Shafiq U, Mukhtar A, Saeed MM. Design of industrial gravity type $\quad$ separators for the hydrocarbons and heavy oil-water separations. Res. J. Chem. Sci. 2015; $\quad$ 5(9):72-75.

13.Odiete WE, Agunwamba JC. Novel design methods for conventional oil-water separators, Heliyon. 2019; 5(5): e01620.

14.Zhang XY, Li Z, Liu KS, et al. Bioinspired multifunctional foam with self-cleaning and oil/water separation. Advanced Functional Materials. 2013;23(22):2881-2886.

15.Zeng Q, Wang Z, Wang X, Zhao Y, Guo X. A novel oil-water separator design and its performance prediction. Journal of Petroleum Science and Engineering 2016; 145:83-94.

16.Han Y, He L, Luo X, Lü Y, Shi K, Chen J, Huang X. A review of the recent advances in design of corrugated plate packs applied for oil-water separation. Journal of Industrial and Engineering Chemistry. 2017; 53:37-50.

17.NurulAiniAmran and Siti Nor Adibah Mustapha (October 26th 2020). Oil-Water Separation Techniques for Bilge Water Treatment, Resources of Water, Prathna ThanjavurChandrasekaran, SalikJavaid, AftabSadiq, IntechOpen.

Muhammad

18.ChenB, Wang B, Mao F, Ke B, WenJ, Tian R, LuC, Review on separation mechanism plate separator. Annals of Nuclear Energy 2020; 144:107548.

19.Le TT, Ngo SI, Lim Y, Park CK, Lee BD, Kim BG, et al. Three-phase Eulerian computational fluid dynamics of air-water-oil separator under off-shore operation. Journal of Petroleum Science and Engineering 2018; 171: 731-747.

20.Boraey MA, A Hydro-Kinematic approach for the design of compact corrugated plate interceptors for the deoiling of produced water. Chemical Engineering and Processing Process Intensification, 2018; 130: 127133

21.Jaworski AJ, Meng G. On-line measurement of separation dynamics in primary separators: Challenges and technical solutions-A review. Journal of Petroleum Science and Engineering 2009; 68: 47-59.

22.Pielkenrood, 2019. Website company: https://www.pielkenrood.net/technologies/

23.FischerAP. Oil/water Separation. St. Paul, Minnesota, United States ofAmerica; 2012.

24.Department for Environment, Food and Rural Affairs (DEFRA).Groundwater Protection Code: Petrol Stations and Other Fuel Dispensing Facilities Involving Underground Storage Tanks", London, UK; 2002.

25.Branchu P, French airport runoff pollution management (water and sludge): Toward a new approach based on constructed wetlands? Case of Aéroports de Paris - Orly

(France). Water Pract. Technol., 2014; 9:20-32.

26.Kundell J, Rasmussen T, Recommendations of the Georgia Board of Regents Scientific_ Panel on Evaluating the Erosion Measurement Standard Defined by the Georgia Erosion and Sedimentation Act. Proceedings of Georgia Water Resources Conference, University of Georgia, 1995; pp. 212.

27. Lye DJ, Rooftop runoff as a source of contamination: A review. Sci. Total Environ., 2009; 407(21): 54295434. 
28.Vivona MA, Mooney G. Remediation of Contaminated Stormwater Canal at Miami International Airport. Water Eng. Manage.,1997; 144 (8): 24-29.

29.Liu B.Stormwater Runoff from Busy Airport Safely Discharged to Prestigious Lake”. Spelstormwater. 2015; February 02https://spel.com.au/2015/02/17/stormwater-runoff-busy-airport-safely-discharged-prestigious-lake/

30.American Petroleum Institute (API) (February 1990). Management of Water Discharges: Design and Operations of Oil-Water Separators (1st ed.). American Petroleum Institute.U.S. Department of Transportation Federal Aviation Administration; 2013. 